\section{Commentary: Gender and outcomes of acute aortic dissection: Instantaneously good, but then?}

\author{
Amedeo Anselmi, $\mathrm{MD}, \mathrm{PhD}$, and \\ Jean-Philippe Verhoye, MD, $\mathrm{PhD}$
}

Since 2006, the GERAADA Registry has reflected the tendencies and outcomes in the practice of surgery for acute type A aortic dissection in many centers from Germany, Austria, Switzerland, and Luxembourg. ${ }^{1}$ It is the expression of a great deal of commitment and represents an invaluable source of information in a field that continues to offer challenges and gratification, surprises, and frustrations. The current prestigious manuscript issued from the GERAADA Registry written by Rylski and coworkers ${ }^{2}$ confirms that acute dissection tends to occur more frequently and earlier in life in men compared with women, underscores that men tend to present with a more severe proximal phenotype (with more frequent need for root replacement), and indicates that despite these dissimilarities, overall early outcomes are similar among genders. Indeed, it has been demonstrated that women present with delayed/less frequent occurrence of acute dissection, possibly as an expression of the protective effects on the cardiovascular system exerted by their hormonal layout. Conversely, it seems that a great value of this Registry lies in illustrating the effects of significant recent progress in surgical treatment, as demonstrated by the low incidence of aggregated mortality in data from as many as 56 centers. The authors correctly highlight advancements in cerebral protection strategies, surgical techniques, and technologies (eg, availability of frozen

\footnotetext{
From the Division of Thoracic and Cardiovascular Surgery, Pontchaillou University Hospital, Rennes, France.

Disclosures: The authors reported no conflicts of interest.

The Journal policy requires editors and reviewers to disclose conflicts of interest and to decline handling or reviewing manuscripts for which they may have a conflict of interest. The editors and reviewers of this article have no conflicts of interest.

Received for publication April 15, 2020; revisions received April 15, 2020; accepted for publication April 15, 2020; available ahead of print May 11, 2020.

Address for reprints: Amedeo Anselmi, MD, PhD, Division of Thoracic and Cardiovascular Surgery, Pontchaillou University Hospital, 35000 Rennes, France (E-mail: amedeo.anselmi@chu-rennes.fr).

J Thorac Cardiovasc Surg 2021;162:536-7

$0022-5223 / \$ 36.00$

Copyright (c) 2020 by The American Association for Thoracic Surgery

https://doi.org/10.1016/j.jtcvs.2020.04.119
}
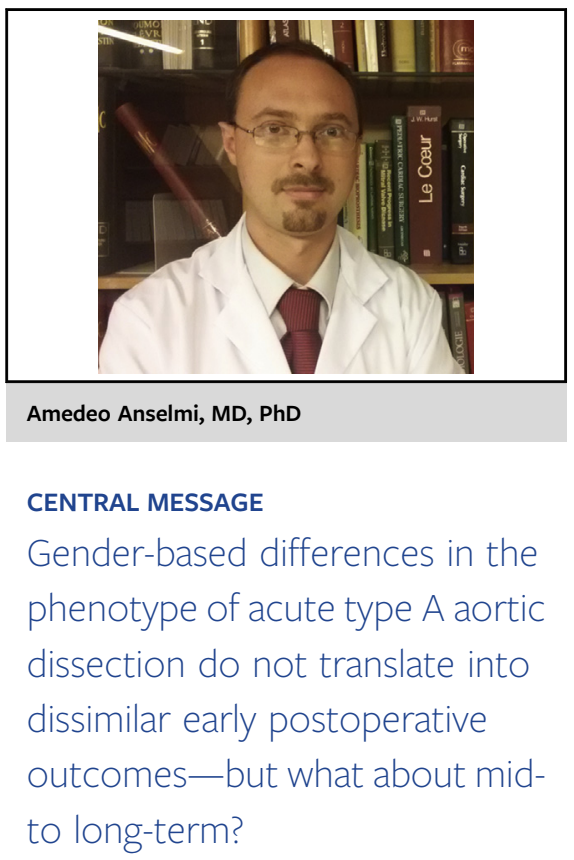

elephant trunk and of modern vascular prostheses, use of reliable glues). In addition, we suggest the increasingly decomplexified attitude toward the use of root replacement surgery, an attitude that has spread in parallel with the democratization of surgical competence in such techniques. A hidden message in the folds of the GERAADA data likely consists in the effectiveness of liberal root replacement as a powerful tool to prevent early mortality in patients with a more aggressive proximal phenotype and, ultimately, to obtain similar outcomes among genders despite differing baseline profiles.

In that sense, and more in general, acute type A dissection represents a field in which the synergy of systematization, standardization, surgical pedagogy, and establishment of a rational referral chain have yielded major ameliorations in early outcomes compared with less recent experiences. ${ }^{3}$ Such tendency has become evident in many reference aortic centers worldwide, including the writers' one. It remains to be understood whether the same conclusions can be applied to lower-volume institutions-a question the GERAADA is well positioned to address. The mean annual volume is actually low- 6 dissections per each of the 56 participating centers-suggesting an "organizational" dispersion, possibly due to "territorial" reasons.

The amount of available data in this registry and the relevant number of patients might be helpful to address some old-yet in a great deal unanswered-questions about seasonality and influence of environmental factors on the occurrence of dissection. We hope that the GERAADA will continue to be extensively exploited and used to provide 
several additional insightful messages. An additional significant drawback is represented by the limited availability of follow-up data beyond the 30th postoperative day. Although the authors' decision to report only patients with complete data is methodologically incontestable, the demonstration of long-term outcomes and their reasoned communication remains a vital asset for contemporary cardiac surgery. In that sense, is the GERAADA a "mutilated" tool?

\section{References}

1. Boening A, Karck M, Conzelmann LO, Easo J, Krüger T, Rylski B, et al. German registry for acute aortic dissection type A: structure, results, and future perspectives. Thorac Cardiovasc Surg. 2017;65:77-84.

2. Rylski B, Georgieva N, Beyersdorf F, Büschb C, Boening A, Haunschild J, et al Gender-related differences in patients with acute aortic dissection type A. J Thorac Cardiovasc Surg. 2021;162:528-35.e1.

3. Berretta P, Patel HJ, Gleason TG, Sundt TM, Myrmel T, Desai N, et al. IRAD experience on surgical type A acute dissection patients: results and predictors of mortality. Ann Cardiothorac Surg. 2016;5:346-51.
See Article page 528.

\section{Commentary: Gender differences in aortic pathology and detection bias}

\author{
Hope E. Cordova, DO, and Dawn S. Hui, MD
}

Health inequality between genders is a well-known phenomenon that has been demonstrated for centuries, first documented in the 1850 s by the British epidemiologist William Farr. ${ }^{1}$ Such differences are clearly demonstrated when comparing overall life expectancy, which has improved in females since the $1890 \mathrm{~s}^{2}$; however, questions remain as to the contributing factors. In this edition of the Journal, Rylski and colleagues ${ }^{3}$ examine gender-related differences in acute aortic dissection, specifically differences in disease presentation, anatomic burden, and surgical outcomes.

We congratulate the authors in examining gender differences in this subset. An editorial series on gender differences in cardiothoracic surgery diseases and outcomes was initiated by the Journal nearly 20 years ago, ${ }^{4}$ and yet still much work remains to be done. A strength of this study is that the data are derived from a multicenter, multinational registry. Findings included that women presented at an older age (average, 5 years older), and that men were more likely to have visceral/renal malperfusion and

\footnotetext{
From the Department of Cardiothoracic Surgery, University of Texas Health Sciences Center at San Antonio, San Antonio, Tex.

Disclosures: The authors reported no conflicts of interest.

The Journal policy requires editors and reviewers to disclose conflicts of interest and to decline handling or reviewing manuscripts for which they may have a conflict of interest. The editors and reviewers of this article have no conflicts of interest.

Received for publication April 15, 2020; revisions received April 15, 2020; accepted for publication April 16, 2020; available ahead of print May 11, 2020.

Address for reprints: Dawn S. Hui, MD, 7703 Floyd Curl Drive, Suite 211L, San Antonio, TX 78229 (E-mail: huid@uthscsa.edu).

J Thorac Cardiovasc Surg 2021;162:537-8

$0022-5223 / \$ 36.00$

Copyright (c) 2020 by The American Association for Thoracic Surgery

https://doi.org/10.1016/j.jtcvs.2020.04.120
}

\section{Check for updates}

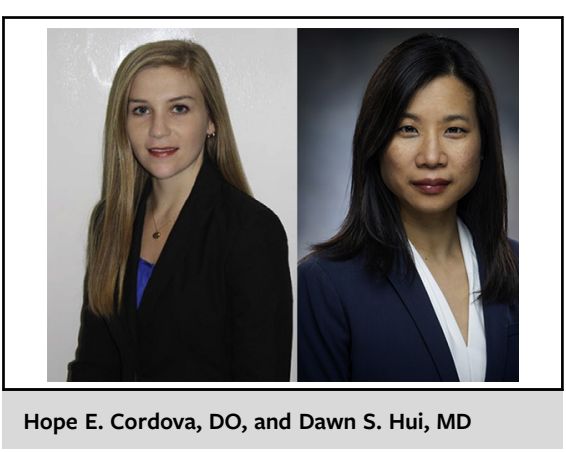

CENTRAL MESSAGE

A registry study suggests gender differences in the clinical and anatomic presentation and surgical intervention of acute type $A$ dissections. We reflect on the potential for study biases.

neurologic dysfunction and to undergo aortic root replacement. Operative mortality was similar.

A question that arises is whether presentation differences truly represent gender-mediated biological differences in disease behavior, or might they reflect differences in detection and/or management. As with all procedure-based registries, there is a potential for survivorship bias when evaluating disease incidence. ${ }^{5}$ With specialized care, there also may be a referral bias. Inclusion in the study of Rylski and colleagues involved 4 preoperative steps: patients had to have been accurately diagnosed, transferred to a German Registry for Acute Aortic Dissection Type A (GERAADA) center, offered surgery, and consented to surgery as a treatment. This meant that the study excluded patients with type A dissection who had a missed diagnosis (whether clinically or due to lack of high-quality, accurately interpreted 